\title{
OUTRA LINGUAGEM, OUTRA ALFABETIZAÇÃO: SENTIDOS DA EDUCAÇÃO EMANCIPADORA EM PAulo FreIRE
}

\author{
Bruna Sola da Silva Ramos \\ Franciane Sousa LadeIRA Aires \\ Universidade Federal de São João del-Rei (UFSJ), São João del-Rei, \\ Minas Gerais, Brasil
}

\begin{abstract}
Resumo: O propósito deste ensaio é refletir sobre outra linguagem e outra alfabetização como forma de expressar sentidos sobre a educação emancipadora, a partir da perspectiva crítica de Paulo Freire. Em sua composição realizou-se o estudo bibliográfico de obras freirianas, privilegiando-se a compreensão dos eixos conceituais que embasam a discussão sobre alfabetização e processos de leitura da palavramundo. Como uma práxis vinculada à criticidade e à conscientização, a alfabetização é aqui discutida em seu viés emancipador, o que permite ao homem assumir-se como presença no mundo e engajar-se, política e responsavelmente, em movimentos transformadores de sua própria realidade.

Palavras-chave: Linguagem. Alfabetização. Educação Emancipadora. Paulo Freire.
\end{abstract}

INTRODUÇÃO

[...] Palavras que me aceitam como sou - eu não aceito. Não aguento ser apenas um sujeito que abre portas, que puxa válvulas, que olha o relógio, que compra pão às 6 da tarde, que vai lá fora, que aponta lápis, que vê a uva etc. etc. Perdoai. Mas eu preciso ser Outros. [...]

(MANOEL DE BARROS, 2002, p. 79) 
O que significa a alguém "ser Outros"? Como lhe é possível "ser Outros"? O que isso tem a dizer sobre linguagem e alfabetização? Inspiradas pelo poeta pantaneiro, somos convidadas a pensar que não nos basta a inércia de uma vida abstrata, adaptada ao gosto do que está posto, dado como pronto. "Perdoai. Mas eu preciso ser Outros". É sina de nossa vocação humana e dela não podemos escapar. Inacabados e conscientes de nosso inacabamento somos potência para o "ser mais", como anunciado em léxico freiriano. E a cada vez que formos "Mais", seremos apenas "Outros". Sujeitos emancipados, a quem não basta saber que "Eva viu a uva", mas "compreender qual a posição que Eva ocupa no seu contexto social, quem trabalha para produzir a uva e quem lucra com esse trabalho" (FREIRE, 2006, p. 56).

É por esse ângulo de abertura e transformação que percebemos a linguagem como mais do que um sistema abstrato e estático, pois que é processo, movimento, acontecimento e interação. Da mesma forma, não nos contentamos com uma visão estreita de alfabetização, como se ela servisse apenas à codificação e à decodificação de símbolos e letras. $\mathrm{O}$ sentido de alfabetização precisa ganhar dimensões mais amplas. Sentimos a alfabetização com o corpo, com a história e com o mundo. Aprendemos letras, sílabas e palavras. Lemos e escrevemos ao passo que nos inscrevemos em nossa própria história - legado que Freire nos deixa para pensarmos o próprio existir humano.

Daí que, contrariando concepções mecanicistas, pensamos uma linguagem outra com sentidos ligados à alfabetização emancipadora. Linguagem e alfabetização feitas de "fonemas da alegria", ou algo em torno do que nos ensina Thiago de Mello:

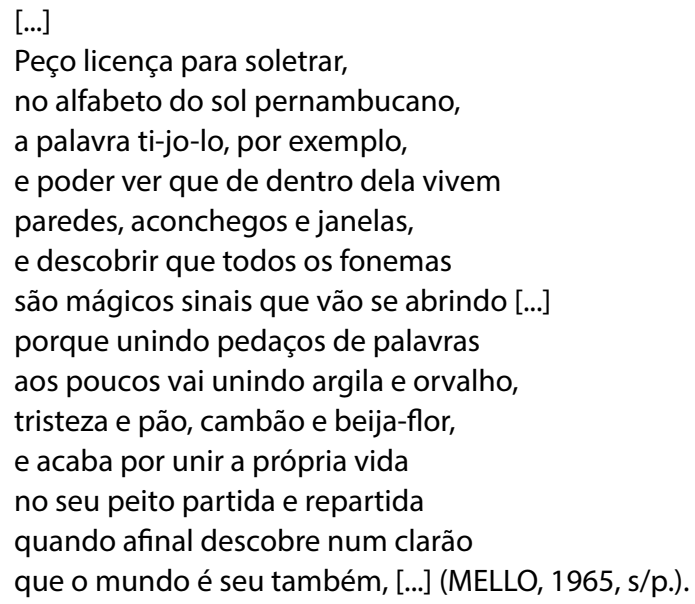


Clarão: argila e orvalho, tristeza e pão, cambão e beija-flor - elementos tão díspares, mas que nos permitem ver o mundo de forma dialógica e dialética. Ler a palavra... Ler o mundo! Não é apenas a descoberta da palavra escrita, mas a palavra da própria realidade. Thiago de Mello (1965) declara seu amor pelas palavras e canta a alfabetização inteirada ao mundo do alfabetizando. Linguagem e alfabetização como fonemas concretos e responsáveis; fonemas que unem vidas e histórias em perspectiva emancipadora.

Mas, o que aqui chamamos de emancipação? Direito antecipado pela maioridade? Uma ação para independência? Um movimento de libertação? Como fio condutor deste ensaio, concebemos a alfabetização emancipadora em Paulo Freire como um ato humano de liberdade e, por isto, um ato crítico, reflexivo e responsável. Não busca apenas a independência do sujeito em seu escopo singular, mas uma libertação em forma de luta coletiva, construída pelo diálogo e objetivada em um processo de transformação de si no mundo, com o mundo e com o outro. É direito sim, mas não pela maioridade, senão pelo devir, pelo"ser mais". É interação, práxis, conscientização; estar no mundo como gente e agente, (re)lendo-o no continuum de seu quefazer responsável.

\section{Primeiros fonemas a soletrar: Paulo Freire e a leitura da palavramundo}

Alfabetização, mesmo numa compreensão superficial, é um exercício através do qual o alfabetizando vai se apoderando, pouco e pouco, do profundo mistério da linguagem. Quer dizer, vai assumindo aquilo que ele já faz quando vem se alfabetizar. Vai assumir a legitimidade daquilo que a gente chama de competência linguística. $O$ alfabetizando, que vem se alfabetizar, já fala. Por isso mesmo é que nunca apareceu um caso de analfabetismo oral. Não existe. Quer dizer, o analfabeto fala. $O$ analfabeto tem uma competência linguística que ele cria, que ele ganha socialmente. É socialmente que a gente fala. Por isso é que ninguém ensina a ninguém falar. Nem ninguém ensina a ninguém a língua. A gente ensina gramática, ensina sintaxe, mas não a dominar a língua. Isso é um exercício social, com as dimensões individuais que ele tem. Numa primeira compreensão, alfabetizar é isso. (PAULO FREIRE, 2001a, p. 126-127)

Em Paulo Freire, alfabetização se torna um conceito amplo e profundo. Toda sua obra é um referencial forte, mas, conforme exposto pelo próprio autor, não é um manual pronto e acabado que deve ser imposto como o fazem os opressores, mas experiências que devem ser recriadas e não apenas transplantadas (FREIRE; MACEDO, 2013). Torres (2014, p. 63) complementa essa ideia ao dizer que as práticas freirianas são "o caminho para novas experiências criadoras, uma vez que não existem receitas válidas para todo tempo e lugar". 
Em busca de uma compreensão rigorosa de alfabetização, afirma Freire que "se eu me preocupo com algo mais do que o sentido gramatical da palavra, do verbo, do substantivo alfabetização, eu descubro que alfabetização não é, não significa simplesmente pôr o alfabeto à disposição do alfabetizando" (FREIRE, 2001a, p. 126), pois "a alfabetização é um marco criador e não memorizador" (FREIRE, 2001a, p. 243).

Em sua tese intitulada Educação e atualidade brasileira, Freire já nos fazia refletir sobre como concebia a alfabetização: "entendendo-se por alfabetização mais que ler e escrever rudimentarmente" (FREIRE, 2003, p. 87). Insistia em dizer que nossas escolas necessitavam de mudanças para serem "não apenas centros de alfabetização de nossos meninos, mas centros onde formem hábitos de solidariedade e de participação. Hábitos de investigação. Disposições mentais críticas" (FREIRE, 2003, p. 90).

Nesse sentido, por toda sua obra, Freire anuncia alguns pressupostos caros à compreensão libertadora da educação: a impossibilidade de um quefazer neutro; a dimensão ética e estética da prática educativa; e o respeito à identidade cultural dos educandos. Todos muito significativos em sua compreensão da alfabetização como um ato de conhecimento e de criação que se constrói quando os alfabetizandos são desafiados a se tornarem sujeitos de seu processo de aprendizagem (FREIRE, 2015).

Freire também pensa a alfabetização em seu caráter de introdução à democratização da cultura e, por isso mesmo, percebe o homem como sujeito e não como objeto, para além de um mero "paciente do processo, cuja virtude única é ter mesmo paciência para suportar o abismo entre sua experiência existencial e o conteúdo que lhe oferecem para sua aprendizagem" (FREIRE, 2014a, p. 136). A alfabetização é, pois, um ato criador, e, como sujeito dessa criação, o homem é capaz de desenvolver a "impaciência, a vivacidade, característica dos estados de procura, de invenção e reivindicação" (FREIRE, 2014a, p. 137).

Para além do simples domínio de técnicas de ler e escrever, Freire anuncia o domínio consciente dessas mesmas técnicas, pois a alfabetização não se pode reduzir a experiências pouco criativas, nas quais os fundamentos das letras e das palavras sejam tratados em esfera puramente mecânica (FREIRE; MACEDO, 2013).

É entender o que se lê e escrever o que se entende. É comunicar-se graficamente. É uma incorporação. Implica não uma memorização visual e mecânica de sentenças, de palavras, de sílabas, desgarradas de um universo existencial - coisas mortas ou semimortas -, mas numa atitude de criação e recriação (FREIRE, 2014a, p. 145). 
Dessa forma, Paulo Freire transcende o conteúdo etimológico de alfabetização, entendendo-a como um dos processos pelo qual o alfabetizando se torna sujeito e não mero objeto. Compreende-a como a relação entre o educando e o mundo, para que este último possa sofrer mediações do primeiro e ambos se transformarem. Em outras palavras, é tomar a história nas próprias mãos, é ler o mundo e reescrever a sociedade ao passo que se lê e escreve a palavra, sendo um dos mecanismos deflagradores da transformação social.

[...] do ponto de vista da libertação, o processo de alfabetização é um ato de conhecimento, um ato criador, no qual o iletrado, tanto como o seu instrutor, desempenha o papel de sujeito conhecedor. Os iletrados não são considerados como "recipientes vazios" ou como simples recipientes. Não são considerados como marginais que devem ser recuperados, mas como homens que estão impedidos de ler e de escrever pela sociedade na qual eles vivem, homens dominados, privados do seu direito de transformar o seu próprio mundo (FREIRE, 1997, p. 24).

Como ato criativo, a alfabetização implica a compreensão crítica da realidade e da própria vida; uma "alfabetização abrangente que é necessariamente política" (FREIRE; MACEDO, 2013, p. 120). Portanto, segundo Freire, não há alfabetização neutra, "enfeitadinha de jasmins". Ela é, em sua essência, um processo político, independente da educadora "saber disso ou não":

A educadora pode bater com o pé no chão, fazer beicinho, dizer "não sou política", e o trabalho dela é político, e, se isso é verdade, o melhor então é que educadora saiba, desde o começo, que faz política, uma coisa que não é fácil. Ela vai ter que optar, e optar é difícil, implica decisão, e decidir, por sua vez, exige ruptura (FREIRE, 2001a, p. 128).

Sendo assim, o processo de alfabetização exige nitidez política. Quando educadores sem essa nitidez se inserem no âmbito da alfabetização "podem, quando muito, ajudar os alunos a ler a palavra, mas são incapazes de ajudá-los a ler o mundo" (FREIRE; MACEDO, 2013, p. 156). O processo de alfabetização tem relação com a maneira com que o educador se engaja na prática para contribuir com quem ainda não lê a palavra.

Em compreensão crítica, o ato de ler "não se esgota na decodificação pura da palavra escrita ou da linguagem escrita", mas "se antecipa e se alonga na inteligência do mundo" (FREIRE, 2001b, p. 11).

A experiência da leitura do mundo que o toma como um texto a ser "lido"e "reescrito" não é na verdade uma perda de tempo, um blá-blá-blá ideológico, 
sacrificador do tempo que se deve usar, sofregamente, na transparência ou na transmissão dos conteúdos, como dizem educadores ou educadoras reacionariamente "pragmáticos". Pelo contrário, feito com rigor metódico, a leitura do mundo que se funda na possibilidade que mulheres e homens ao longo da longa história criaram de inteligir a concretude e de comunicar o inteligido se constitui como fator indiscutível de aprimoramento da linguagem (FREIRE, 2014b, p. 46-47, grifo do autor).

Daí que linguagem e realidade se relacionam, de forma dinâmica, em um ato político de conhecimento e de criação. Esse movimento converge para uma posição curiosa e crítica que descortina um empenho da leitura do mundo e da palavra (FREIRE, 2001b). Ou seja, a alfabetização assinala uma ação desencadeada antes mesmo da descoberta da palavra.

[...] o processo de alfabetização válido entre nós é aquele, que [...] não se satisfaz apenas [...] com a leitura da palavra, mas que se dedica também a estabelecer uma relação dialética entre a leitura da palavra e a leitura do mundo, a leitura da realidade. A prática da alfabetização tem que partir exatamente dos níveis de leitura do mundo, de como os alfabetizandos estão lendo sua realidade, porque toda leitura do mundo está grávida de um certo saber. Não há leitura do mundo que não esteja emprenhada pelo saber, por certo saber (FREIRE, 2001a, p.134).

A leitura do mundo "grávida de saber" é uma forma de escrever ou de reescrever o mundo, "quer dizer, de transformá-lo através de nossa prática consciente" (FREIRE, 2001b, p. 20). É práxis de leitura da palavra; também é práxis de leitura do mundo, pois "a leitura da palavra, da frase, da sentença, jamais significou uma ruptura com a'leitura' do mundo" (FREIRE, 2001b, p. 15).

Leitura do mundo e leitura da palavra não se separam completamente, "a leitura do mundo precede sempre a leitura da palavra e a leitura desta implica a continuidade da leitura daquela" (FREIRE, 2001b, p. 20). A alfabetização, sendo o processo de aprendizagem da leitura da palavra, iniciase a partir da leitura do mundo e a ela retorna, o que significa dizer "reler o mundo depois de ter lido a palavra" (FREIRE, 2001a, p. 134). Sendo assim, "ler a palavra e aprender como escrever a palavra, de modo que alguém possa lê-la depois, são precedidos do aprender como 'escrever' o mundo, isto é, ter a experiência de mudar o mundo e de estar em contato com o mundo" (FREIRE; MACEDO, 2013, p. 83).

Como um movimento constante do mundo à palavra e da palavra ao mundo, a alfabetização é percepção das relações entre o texto e o contexto, o que Freire denomina leitura da palavramundo (FREIRE, 2001b). Portanto, a alfabetização é o esforço no sentido de uma compreensão que mantém viva 
a relação entre leitura do mundo e leitura da palavra. Nessa perspectiva, a palavra se torna elemento central, mas não tem o sentido de uma doação que o educador faz aos educandos; ao contrário, "representa essencialmente temas de discussão, pois sua existência depende de seu significado concreto referido às situações vividas" (OLIVEIRA; DOMINICE, 2014, p. 240).

Esta palavra, portanto, não deve ser imposta de cima para baixo, mas gerada de dentro para fora no e do próprio contexto, no e do próprio diálogo, com os alfabetizandos: "palavras do Povo, grávidas de mundo" (FREIRE, 2001b, p. 20). Por isso, não há palavra verdadeira que não seja práxis, pois dizer a palavra verdadeira é um ato a favor da transformação do mundo (FREIRE, 1987). Dizer/ler a palavra é um quefazer educativo. É ação cultural. Por isto, são as palavras geradoras, são os temas geradores.

Conforme afirma Torres (2014, p. 44): "É reconhecer a palavra que escutou sempre porque é sua palavra. O homem aprende a admirar e admirarse. E, nessa dialética de admiração, descobre o outro". São palavras e temas geradores de clarificação, de conscientização, de relações de alteridade, de práxis, por se constituírem os sujeitos como partícipes do diálogo, não só com os alfabetizandos, mas com a própria realidade.

Nessa perspectiva, Freire e Macedo (2013) apontam que a linguagem e a alfabetização jamais devem ser concebidas apenas como ferramentas de comunicação, pois a "linguagem vem de envolta com a ideologia e, por essa razão, tem-se que lhe dar proeminência em qualquer pedagogia radical que se proponha propiciar espaço para a emancipação do aluno" $(2013$, p. 150).

\section{NOTAS POR UMA ALFABETIZAÇÃO EMANCIPADORA}

Outra linguagem, outra alfabetização - em perspectiva emancipadora - é palavra unida à história, à vida, ao mundo. É assim que Paulo Freire nos instiga a pensar sobre o uso da língua $\mathrm{e}(\mathrm{m})$ seu ensinar, aprender e viver. A potencialidade emancipadora da alfabetização em Freire é um quefazer humano que a desvincula de qualquer técnica mecanicista. Freire abre a vida para a curiosidade, para a criticidade e a conscientização, a fim de que a vida use e se dê em palavras de transformação. A alfabetização é o conhecimento, a criação e a nitidez política iluminando o caminho dos homens. Também é diálogo: texto $\mathrm{e}(\mathrm{m})$ contexto.

Com Freire, a palavra se torna gerativo-geradora. A palavra geradora é carregada de conteúdo existencial, de sentidos para quem a pronuncia, capaz de se desmembrar em pedaços, em "famílias" que se descobrem geradoras, criadoras de outras palavras. Da palavra gerativa germina a leitura do mundo, que enuncia e pronuncia a palavra geradora prenhe de sentidos para a 
leitura da palavra. Nesse movimento de gerar mundo e palavra, encontramos o sentido de tomada de posicionamento crítico e o compromisso com a humanização, com o devir, com o "ser mais".

Assim, pensamos a alfabetização como ação dinâmica, crítica, reflexiva, responsável, alteritária; ação para a liberdade em luta, para o diálogo - para o outro, com o outro - que descortina a transformação no mundo e com o mundo. É uma alfabetização que se supõe na interatividade, na ação-reflexão, no nosso inacabamento, enfim, permitindo-nos sermos o que devemos ser: cada vez mais humanos.

É com este pensamento que defendemos uma alfabetização emancipadora, por compreendermos que tal termo consegue abraçar os demais - defendidos por Freire e também denominados por ele como alfabetização crítica, alfabetização política, alfabetização problematizadora -, pois, a nosso ver, emancipação diz respeito à criticidade, à política, à autonomia e à conscientização.

Compreendemos a alfabetização emancipadora como um processo dinâmico, interativo e prazeroso, uma atividade calorosamente responsável por vincular vida à aprendizagem ao entretecer relações de alteridade, abertura ao diálogo, ao falar-ouvir responsável, que permitem a agência no mundo, a criação de cultura, instigam a curiosidade, a pluralidade de sentidos, o compartilhamento de ideias e a boniteza de ler a palavramundo. Uma atividade polissêmica que permite aos educandos falarem de si e de seus lugares, que os instiga a refletirem sobre quem estão sendo e sobre o lugar em que vivem, exigindo o respeito de seus posicionamentos, de suas inventividades, enfim, de suas singularidades tão plurais.

A alfabetização emancipadora é uma ação concreta que une texto e contexto, mundo e palavra. Exige um quefazer responsável dos educadores no sentido de permitir a criação e a (re)invenção dos sentidos ao se (re)ler o mundo e a palavra. Por isso, afirma Freire "ninguém chega lá partindo de lá, mas daqui" (FREIRE; MACEDO, 2013, p. 80, grifo dos autores). É assim que se pode construir um processo de alfabetização: buscando na própria contextura, na própria cultura, os recursos para uma proposta educativa.

Todavia, a alfabetização emancipadora não representa um ofuscamento do "lá", pelo contrário, representa um descortinamento do próprio contexto para agir e refletir, auxiliado por uma compreensão ativa ao partir de seu entorno e expandir-se sobre o seu mundo e o mundo dos outros, do micro para o macro. Em outras palavras, a práxis da leitura do mundo se faz pela força do local para transformar o global. Através de seu mundo, outros conhecer. 
Daí que a cultura é muito importante para a alfabetização, uma vez que esta é uma expressão e uma dimensão daquela, logo "não se pode desenvolver um trabalho de alfabetização fora do mundo da cultura" (FREIRE; MACEDO, 2013, p. 85). E ambas, cultura e alfabetização, devem manter-se em relação, para que educadores e educandos produzam, recriem significados e sentidos e transformem suas vidas, suas histórias. Em outras palavras, a alfabetização emancipadora permite o conhecimento, o questionamento e a criação sobre a realidade local, como se fossem camadas que, sendo conhecidas, refletidas, ressignificadas, descamam a realidade global.

No entanto, "jamais devemos tomar a alfabetização como a deflagradora da transformação social. A alfabetização, como conceito global, é apenas parte do mecanismo deflagrador da transformação" (FREIRE; MACEDO, 2013, p. 122). Por outro lado,

se a alfabetização não é fazedora de cidadania, a alfabetização e sobretudo uma certa forma de trabalhar a alfabetização, pode constituir-se num fator, numa espécie de empurrão necessário na busca da cidadania. É preciso ficar claro que o fato de ler hoje o que não lia ontem, em termos de palavras, não significa que ninguém virou cidadão (FREIRE, 2001a, p. 132).

Por tudo isso, Freire traz uma nova perspectiva para a Educação. $O$ educador expõe seu pensamento sobre o processo de alfabetização, em que, não sendo um processo mecanicista, revela potencialidades emancipadoras para um processo de conscientização. Nesse sentido, Oliveira e Dominice (2014, p. 240) comentam que "alfabetização e conscientização [...] são os dois polos inseparáveis dessa pedagogia que questiona o próprio conceito de educação e modifica a relação tradicional entre professor e aluno". Desse modo, o processo de conscientização prepara os homens para lutarem a favor de sua humanização: é comprometimento (FREIRE, 1987) - jamais uma pílula mágica para a mudança do mundo (FREIRE, 2006); passa pelo desenvolvimento da consciência crítica e exige engajamento da ação transformadora, sendo o objetivo primeiro de toda a Educação (FREIRE, 1979).

Com Paulo Freire trazemos à luz a força e a vitalidade da palavra, já que "existir, humanamente, é pronunciar o mundo" (FREIRE, 1987, p. 78). Ao pronunciar o mundo, crítica e responsivamente, o homem vai se constituindo na transitividade de sua consciência, o que lhe permite ir além das formas ingênuas de compreender a sua realidade e perceber-se "corpo consciente"; sujeito cuja consciência intencionada ao mundo capta a realidade da qual faz parte e sobre a qual se debruça. Esse é o movimento que sustenta e dá vida a uma proposta de alfabetização emancipadora. 
Fonemas PARA "ENCERRAR"

Neste momento em que "celebramos" vinte anos da morte do educador Paulo Freire, como um brinde à sua farta e fértil vida educadora, defendemos a atualidade e relevância de sua proposta de alfabetização emancipadora; aquela que permite sermos sujeitos - educadores e educandos - utópicos na grande temporalidade, geradores de palavras e sentidos para si e para o outro, no e com o mundo.

O sonho possível de uma alfabetização emancipadora se compromete com o anúncio da utopia e da esperança para que a valorização da cultura e dos saberes do educandos, aliada à promoção da ingenuidade em criticidade, permita a incorporação da palavramundo, amplie as possibilidades de inserção dos sujeitos em sua própria realidade e potencialize suas agências no mundo.

Ao assumirmos o ideal emancipador de Paulo Freire, vemos sentido forte para refletirmos sobre - e quiçá reinventarmos - nossa práxis no campo da alfabetização. Nestes tempos em que a complexa contextura social e política tende a ofuscar a ação humana e a agravar a distorção de sua própria vocação, reafirmamos nossa crença e nossa luta em prol de uma educação feita de outra linguagem e outra alfabetização.

\section{ANOTHER LANGUAGE, ANOTHER LITERACY: SENSES OF PAULO FREIRE'S EMANCIPATORY EDUCATION}

ABSTRACT:The purpose of this essay is to reflect on another language and another literacy as a way of expressing meanings about emancipatory education, from Paulo Freire's critical perspective. In this text a bibliographical study of Freirian works was carried out, privileging the understanding of the conceptual axes which support the discussion about literacy and reading processes of the wordworld. As a praxis linked to criticism and to awareness, literacy is here discussed in its emancipatory bias, which allows the individual to assume itself as a presence in the world and to engage, politically and responsibly, in transformative movements of its own reality.

KEYWORDs: Language. Literacy. Emancipatory Education. Paulo Freire. 
OTRO LENGUAJE, OTRA ALFABETIZACIÓN: SENTIDOS DE LA EDUCACIÓN EMANCIPADORA EN PAULO FREIRE

Resumen: El objetivo de este ensayo es reflexionar sobre otro lenguaje y otra alfabetización como formas de expresar sentidos sobre la educación emancipadora, desde la perspectiva crítica de Paulo Freire. Para la composición de este estudio se desarrolló un estudio bibliográfico de obras freireanas, privilegiando la comprensión de los ejes conceptuales que fundamentan la discusión sobre alfabetización y procesos de lectura de la palabra mundo. Como una praxis vinculada a la criticidad y a la concienciación, la alfabetización es aquí discutida en su papel emancipador, lo que le permite al hombre asumirse como presencia en el mundo y participar, política y responsablemente, de los movimientos transformadores de su propia realidad.

Palabras Clave: Lenguaje. Alfabetización. Educación Emancipadora. Paulo Freire.

\section{REFERÊNCIAS}

BARROS, M. de. Retrato do artista quando coisa. 3. ed. Rio de Janeiro: Record, 2002. FREIRE, P. Conscientização: teoria e prática da libertação - uma introdução ao pensamento de Paulo Freire. São Paulo: Cortez \& Moraes, 1979.

. Pedagogia do oprimido. 17. ed. Rio de Janeiro: Paz e Terra, 1987.

. O processo de alfabetização política. Revista da FAEEBA, Salvador, n. 7, p. 1932, jan./jun.1997.

. Pedagogia dos sonhos possíveis. Organização Ana Maria Araújo Freire. São Paulo: Editora UNESP, 2001a.

. A importância do ato de ler: em três artigos que se completam. 41. ed. São Paulo: Cortez, 2001b.

Educação e atualidade brasileira. 3. ed. São Paulo: Cortez; Instituto Paulo Freire, 2003.

. A educação na cidade. 7. ed. São Paulo: Cortez, 2006.

. Educação como prática da liberdade. 36. ed. São Paulo: Paz e Terra, 2014a.

. Pedagogia da indignação: cartas pedagógicas e outros escritos. Organização e participação Ana Maria Araújo Freire. São Paulo: Paz e Terra, 2014b.

. Cartas a Cristina: reflexões sobre minha vida e minha práxis. Organização e notas de Ana Maria Araújo Freire. 2. ed. São Paulo: Paz e Terra, 2015.

FREIRE, P.; MACEDO, D. Alfabetização: leitura do mundo, leitura da palavra. Tradução Lólio Lourenço de Oliveira. 6. ed. Rio de Janeiro: Paz e Terra, 2013. 
MELLO, T. de. Faz escuro mas eu canto, porque amanhã vai chegar. Rio de Janeiro: Civilização Brasileira, 1965.

OLIVEIRA, R. D. de; DOMINICE, P. Freire: desvelar. In: TORRES, C. A. Diálogo e práxis educativa: uma leitura crítica de Paulo Freire. Tradução de Mônica Mattar Oliva. São Paulo: Edições Loyola, 2014, p. 239-245.

TORRES, C. A. Diálogo e práxis educativa: uma leitura crítica de Paulo Freire. Tradução de Mônica Mattar Oliva. São Paulo: Edições Loyola, 2014.

Bruna Sola da Silva Ramos: Professora Adjunta do Departamento de Ciências da Educação; docente-pesquisadora do Programa de Pós-Graduação em Educação, da Universidade Federal de São João del-Rei (UFSJ), em Minas Gerais. Líder do Grupo de Estudos Críticos do Discurso Pedagógico (GECDiP). Conselheira de Educação do município de São João del-Rei/MG. Seus eixos de interesse são Educação-Linguagem; Formação-Prática educativa; Crítica-Política educacional, sob a égide do diálogo com as teorias humanas de Paulo Freire e Mikhail Bakhtin.

E-mail: brunasola@ufsj.edu.br

Franciane Sousa Ladeira Aires: Mestranda em Educação pela Universidade Federal de São João del-Rei, tendo como orientadora a Profa. Dra. Bruna Sola da Silva Ramos. Pesquisadora do grupo de pesquisa GECDiP (Grupo de Estudos Críticos do Discurso Pedagógico). De 2008 a 2014 foi professora dos anos iniciais do Ensino Fundamental na rede de ensino da prefeitura de Prados.

E-mail: francianeladeira@hotmail.com 